\title{
Tratamento térmico de lodo anaeróbio com utilização do biogás gerado em reatores UASB: avaliação da autossustentabilidade do sistema e do efeito sobre a higienização e a desidratação do lodo
}

Thermal treatment of anaerobic sludge utilizing biogas produced in UASB reactors: evaluation of system self-sustainability and the effect on sludge hygienization and dehydration

\section{Eduardo Sales Machado Borges}

Engenheiro Civil. Doutor em Saneamento, Meio Ambiente e Recursos Hídricos pela Universidade Federal de Minas Gerais (UFMG). Professor da Escola Agrotécnica Federal de Barbacena

\section{Valéria Martins Godinho}

Bióloga. Mestre em Saneamento, Meio Ambiente e Recursos Hídricos pela UFMG. Professora do Instituto de Educação Superior de Manhuaçu

\author{
Deneb Oliveira Bejar
}

Engenheira Civil. Mestre em Saneamento, Meio Ambiente e Recursos Hídricos pela UFMG

\section{Carlos Augusto de Lemos Chernicharo}

Engenheiro Civil e Sanitarista. Doutor em Engenharia Ambiental pela Universidade de Newcastle upon Tyne, UK. Professor Adjunto do Departamento de Engenharia Sanitária e Ambiental da UFMG

\section{Resumo}

O presente trabalho objetiva avaliar a eficiência do biogás gerado em reatores UASB como fonte de energia para higienização térmica do lodo excedente, atentando-se ainda para a autossustentabilidade do sistema e para a avaliação do desaguamento do lodo tratado termicamente. Foi desenvolvido em um aparato experimental em escala de demonstração constituído de reator UASB, reservatório de biogás, reator térmico e leitos de secagem. A autossustentabilidade foi verificada por meio de balanço térmico teórico e de testes experimentais de higienização térmica. Estes testes indicaram que o aproveitamento da energia térmica do biogás foi suficiente para aquecer o lodo em temperaturas de 55 a $65^{\circ} \mathrm{C}$, durante três a cinco horas, possibilitando a completa eliminação de ovos viáveis de helmintos. No entanto, o processo de desidratação se mostrou muito mais difícil para o lodo tratado termicamente.

Palavras-chave: biogás; desidratação de lodo anaeróbio; higienização térmica; lodo anaeróbio; ovos de helmintos; reatores UASB.

\section{Abstract}

The objective of this research was to determine how effectively biogas produced in UASB reactors could be used as a source of heat for the thermal hygienization of excess anaerobic sludge, whether the system can operate on a self-sustained basis and how the dehydration of the thermally treated sludge behave. The experiments were conducted in a demonstration-scale setup comprising UASB reactor, biogas holder, thermal reactor and sludge drying beds. The selfsustainability of the system was evaluated by the system's theoretical thermal balance and by experimental hygienization tests. These tests indicated that the recovery of thermal energy from the biogas was sufficient to heat the sludge at temperatures in the range of 55 to $65^{\circ} \mathrm{C}$, for three to five hours, allowing the complete elimination of viable helminth eggs. However, the dehydration process showed to be much more difficult for the thermally treated sludge.

Keywords: biogas; anaerobic sludge dehydration; thermal hygienization; anaerobic sludge; helminth eggs; UASB reactor 


\section{Introdução e objetivos}

A legislação ambiental internacional, no que se refere ao gerenciamento de lodo, vem se desenvolvendo rapidamente nos últimos anos e tornando-se cada vez mais rigorosa e restritiva. Os princípios da reciclagem e das técnicas ambientalmente corretas foram adotados pelas Nações Unidas e implementados na Agenda 21, na conferência do Rio de Janeiro, em 1992 (WEISZ et al, 2000). Segundo Weisz et al (2000), algumas das principais tendências atuais referentes à disposição final do lodo de ETE são: utilização segura de nutrientes e material orgânico na agricultura, redução de gastos com energia, desinfecção do lodo, aumento dos custos com incineração, sociedade mais crítica e exigente com relação a incômodos causados pelo lodo (geração de odores, possibilidade de propagação de doenças etc.) e restrições quanto ao aterramento do material.

Porém, embora mais exigentes, as agências ambientais têm incentivado o emprego agrícola do lodo, desde que apresente características adequadas a esta finalidade. Uma das exigências quanto às qualidades requeridas é a sua higienização, a qual pode ser alcançada empregando-se mecanismos químicos, físicos e biológicos aplicados combinada ou isoladamente.

Além da higienização, o lodo também deve passar por uma etapa de desaguamento, de modo a reduzir o volume e, consequentemente, os custos de transporte, permitindo, assim, que haja viabilidade econômica para o seu uso. O desaguamento consiste na redução do teor de umidade do lodo e, por conseguinte, na elevação da concentração de sólidos totais.

O teor de sólidos a ser alcançado ao final do processo de desidratação e o tempo necessário para atingir esse teor dependem do tipo de lodo a ser desaguado e do processo utilizado. Dessa forma, uma das técnicas mais utilizadas para desaguamento do lodo é o leito de

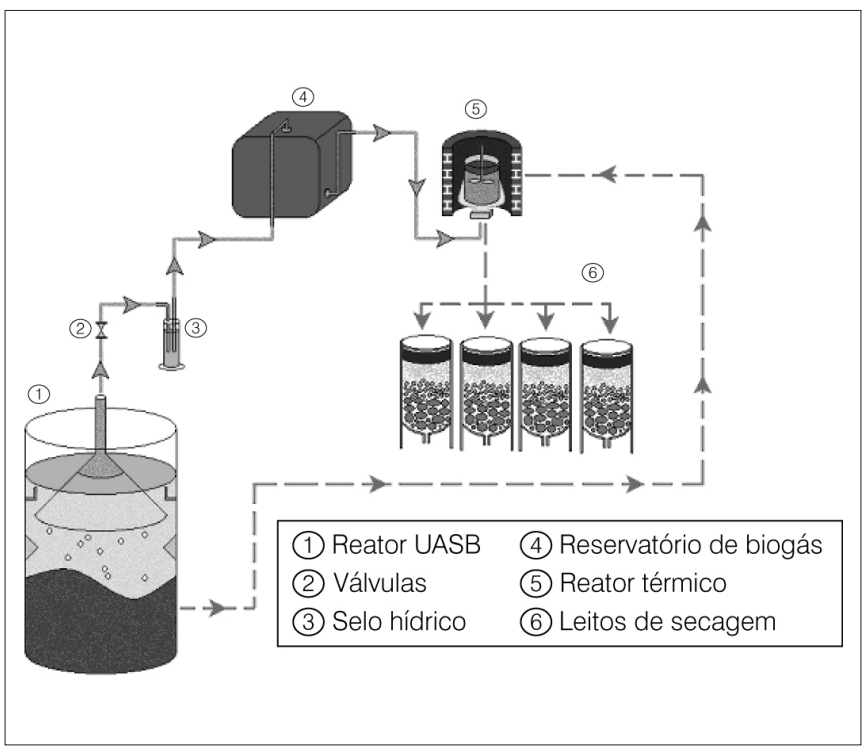

Figura 1 - Configuração esquemática do aparato experimental secagem. Neste sistema, a drenagem e a evaporação são os mecanismos de remoção de umidade.

No caso do desaguamento de lodos submetidos a uma etapa prévia de tratamento térmico, as informações contidas na literatura são divergentes. Anderson et al (2002) mostram que o tratamento de hidrólise térmica em temperaturas na faixa de $150^{\circ} \mathrm{C}$ aumenta significativamente a drenagem deste material. Por outro lado, no caso de pré-tratamento térmico a baixas temperaturas, França (2002) verificou que o desaguamento, em leitos de secagem, de lodo de Reator Anaeróbio de Leito Fluidificado (RALF) submetido ao tratamento térmico em termo-hidrolizador, durante 72 horas, a uma temperatura entre 60 e $75^{\circ} \mathrm{C}$, é piorado.

Nesse contexto, o presente trabalho objetiva avaliar, a partir de um sistema simplificado de tratamento de esgotos e de higienização de lodo, o emprego do biogás gerado em reatores UASB como fonte de energia térmica para higienização térmica do lodo anaeróbio excedente, a diferentes tempos e temperaturas de aquecimento, empregando-se ovos de Ascaris lumbricoides como micro-organismo indicador, atentando-se ainda para a autossustentabilidade do sistema. Objetiva, ainda, avaliar a desidratação do lodo tratado termicamente, aplicando-se diferentes cargas de sólidos em leitos de secagem.

\section{Material e métodos}

\section{Aparato experimental}

O trabalho experimental foi desenvolvido no Centro de Pesquisa e Treinamento em Saneamento (CePTS) UFMG/COPASA, implantado junto à ETE Arrudas, em Belo Horizonte, sendo o aparato, em escala de demonstração, constituído por um reator UASB de $23 \mathrm{~m}^{3}$, um reservatório de biogás de aproximadamente $8 \mathrm{~m}^{3}$, um reator térmico de 220 L e leitos de secagem em formato cilíndrico, confeccionados em fibra de vidro, com as seguintes características principais: diâmetro $=0,60 \mathrm{~m}$; altura útil $=0,35 \mathrm{~cm}$; camada drenante $=1,00 \mathrm{~m}$, conforme preconiza a Norma NBR 12209/92 da ABNT. Apresenta-se, na Figura 1, a disposição do aparato experimental, destacando-se os sistemas de coleta, armazenamento e queima do biogás, além do reator térmico de lodo e dos leitos de secagem.

\section{Operação das unidades experimentais}

Como neste sistema de tratamento de esgotos o biogás é produzido continuamente e o descarte do lodo é realizado em bateladas, para se atingir as condições de trabalho desejadas o biogás produzido foi armazenado para posterior queima no momento do tratamento térmico do lodo. Este armazenamento permitiu a aplicação de pressão no biogás no decorrer do processo de queima, o que propiciou um aumento da vazão de biogás no queimador e, consequentemente, elevação de temperatura em intervalos de 
tempo mais reduzidos, tendo como consequência menores períodos de tratamento do lodo. As pressões empregadas no decorrer dos ensaios situaram-se entre 2,0 e 2,5 cm de coluna d'água, tendo o tratamento térmico apresentado capacidade de se desenvolver por um período em torno de sete horas.

Objetivando-se avaliar a autossustentabilidade do sistema, empregou-se como referência a seguinte rotina operacional:

1) armazenar o volume de biogás produzido em 24 horas;

2) descartar para o reator térmico o volume de lodo a ser tratado, também equivalente à produção de um dia;

3) aplicar pressão no reservatório de biogás, colocando-se pesos sobre este, no decorrer do processo de queima do biogás;

4) no decorrer do tratamento térmico, coletar as amostras de lodo para análise.

Uma vez higienizado, buscou-se a redução da água contida no lodo. Dessa forma, o lodo seguiu para a etapa de desidratação em leitos de secagem. No entanto, testes preliminares indicaram a necessidade de incluir uma etapa de sedimentação no protocolo de testes. Sendo assim, para os testes de desidratação do lodo, a rotina operacional foi alterada, incluindo-se uma etapa de sedimentação anterior à higienização térmica, o que elevou a concentração de sólidos totais de 3,3 para 5\%. Após a sedimentação, o lodo era higienizado e encaminhado para leitos de secagem.

A aplicação de diferentes cargas de sólidos nos leitos de secagem, de lodo in natura e de lodo tratado termicamente, permitiu verificar o comportamento de secagem do lodo higienizado. Foram aplicadas duas cargas de sólidos diferentes nos leitos de secagem (5 e $10 \mathrm{kgST} / \mathrm{m}^{2}$ ).

\section{Análises parasitológicas}

Objetivando-se avaliar a eficiência da higienização do lodo por via térmica a partir da queima do biogás, optou-se por utilizar ovos de helmintos, especialmente de Ascaris lumbricoides, como organismo indicador, pois são altamente resistentes a condições ambientais adversas e encontrados na população com elevada frequência. Para se obter uma quantidade representativa de ovos de Ascaris no lodo a ser analisado, foi necessária uma etapa de trabalho bastante ampla, que incluiu desde a obtenção de fêmeas adultas de Ascaris lumbricoides, retiradas de fezes de crianças infectadas, até a extração dos ovos do útero destes vermes. Estes foram então centrifugados, estocados em tubos e preservados a $4^{\circ} \mathrm{C}$.

Após realização dos ensaios e coleta das amostras, elas foram processadas em laboratório, empregando-se o Método de Meyer (MEYER; MILLER; KANESHIRO, 1978) para a recuperação dos ovos de Ascaris lumbricoides, verificando-se, posteriormente, a viabilidade dos mesmos por meio de incubação. Sendo assim, após o término do período de incubação (28 dias), à temperatura constante de $28^{\circ} \mathrm{C}$, procedia-se à leitura das câmaras, em triplicata, verificando-se o percentual de ovos viáveis e não viáveis, para cada amostra coletada.

No decorrer do trabalho, considerou-se ovo viável aquele que atingiu o estágio final de desenvolvimento, com a formação de larva, e ovo não viável aquele que atingiu qualquer outro estágio de desenvolvimento, mas não se diferenciou em larva após os 28 dias de incubação, período que correspondia ao tempo ótimo definido para a diferenciação dos ovos até o estágio de larva móvel.

\section{Protocolo dos testes de higienização}

Para realização dos ensaios, inoculou-se uma solução de ovos de Ascaris lumbricoides no lodo a ser tratado termicamente, almejandose, a partir do seu teor estimado de sólidos, uma concentração representativa do número de ovos a serem recuperados. Durante os ensaios, o lodo foi mantido em constante agitação, visando a minimizar a sedimentação de sólidos e a formação de gradiente de temperatura ao longo da altura do volume de lodo aquecido, uma vez que o queimador de biogás foi instalado sob o reator térmico. Após a contaminação, homogeneização e coleta de uma primeira amostra (tempo "zero" de aquecimento - temperatura ambiente), iniciava-se o aquecimento do lodo, no decorrer do qual as demais amostras eram coletadas em intervalos definidos de tempo, conforme apresentado na Tabela 1.

\section{Avaliação da autossustentabilidade do sistema}

\section{Avaliação da produção diária de metano}

Conforme Chernicharo (1997), a produção teórica de metano pode ser determinada pela Equação 1.

$D Q O_{C_{4}}=Q_{m e ́ d} \times\left[\left(S_{0}-S\right)-\left(\left(Y_{o b s} \times K_{\text {sólidos }}\right) \times\left(S_{0}-S\right)\right)\right] \quad$ Equação 1

Na qual:

$\mathrm{DQO}_{\mathrm{CH}_{4}}$ : carga de DQO convertida em metano $\left(\mathrm{kgDQO}_{\mathrm{CH}_{4}} / \mathrm{d}\right)$;

$Q_{\text {méd }}$ : vazão média de esgoto afluente $\left(\mathrm{m}^{3} / \mathrm{d}\right)$;

$S_{0}$ : concentração de $\mathrm{DQO}_{\text {total }}$ afluente $\left(\mathrm{kgDQO} / \mathrm{m}^{3}\right)$;

$S$ : concentração de $\mathrm{DQO}_{\text {filtrada }}$ efluente $\left(\mathrm{kgDQO} / \mathrm{m}^{3}\right)$;

$Y_{o b s}$ : coeficiente de produção de sólidos no sistema (kgSVT/ $\mathrm{kgDQO}_{\text {removida }}$ );

$\mathrm{K}_{\text {sólidos }}$ : fator de conversão de STV em DQO (1,42 kgDQO/ kgSVT).

Tabela 1 - Temperaturas e tempos de aquecimento referentes a ensaios realizados no decorrer do processo de higienização do lodo

\begin{tabular}{ccc} 
Amostras coletadas & $\begin{array}{c}\text { Tempo de } \\
\text { aquecimento (horas) }\end{array}$ & $\begin{array}{c}\text { Temperatura no } \\
\text { instante da coleta }\left({ }^{\circ} \mathrm{C}\right)\end{array}$ \\
1 & 0 & 25 \\
2 & 3 & 55 \\
3 & 5 & 67 \\
\hline
\end{tabular}


Para se obter a produção volumétrica de biogás, aplica-se a Equação 2 (CHERNICHARO, 1997).

$Q_{\mathrm{CH}_{4}}=\frac{D Q O_{\mathrm{CH}_{4}}}{K(t)}$

Equação 2

Na qual:

$Q_{\mathrm{CH}_{4}}$ : produção de metano (L/d);

$\mathrm{K}(\mathrm{t})$ : fator de correção para a temperatura operacional do reator $\left(\mathrm{kgDQO} / \mathrm{m}^{3}\right)$.

Uma vez que o fator de correção $\mathrm{K}(\mathrm{t})$ varia com a temperatura operacional do reator, esta variação é considerada na Equação 3 (CHERNICHARO, 1997).

$K(t)=\frac{\left(P_{a t m} \times K_{C_{4}}\right)}{[R \times(273+t)]}$ Equação 3

Na qual:

$\mathrm{P}_{a t m}$ : pressão atmosférica ( $\left.1 \mathrm{~atm}\right)$;

$\mathrm{K}_{\mathrm{CH}_{4}}$ : DQO correspondente a um mol de $\mathrm{CH}_{4}\left(64 \mathrm{gDQO} / \mathrm{m}^{3}\right)$;

R: constante dos gases $\left(0,08206 \mathrm{~atm} . \mathrm{L} / \mathrm{mol} .{ }^{\circ} \mathrm{K}\right)$;

t: temperatura operacional do reator $\left({ }^{\circ} \mathrm{C}\right)$.

\section{Avaliação da produção diária de lodo}

Segundo Chernicharo (1997), a produção teórica diária de lodo no sistema pode ser avaliada pela Equação 4.

$L_{\text {removida }}=\left(S_{0}-S\right) \times Q_{\text {med }}$.

Equação 4

Na qual:

$\mathrm{L}_{\text {removida }}$ : carga média de DQO removida no sistema $\left(\mathrm{kgDQO}_{\text {removida }} / \mathrm{d}\right)$.

$P_{\text {lodo }}=Y_{\text {obs }} \times L_{\text {removida }}$

Equação 5

Na qual:

$\mathrm{P}_{\text {lodo }}$ : produção de sólidos no sistema ( $\left.\mathrm{kgST} / \mathrm{d}\right)$.

$V_{l o d o}=\frac{P_{l o d o}}{(\gamma \times C)}$

Equação 6

$\mathrm{Na}$ qual:

$\mathrm{V}_{\text {lodo }}$ : produção de lodo $(\mathrm{L} / \mathrm{d})$;

$\gamma$ : densidade do lodo $=1020 \mathrm{~kg} / \mathrm{m}^{3}$;

C: concentração do lodo (\%).

\section{Produção e demanda teóricas de energia térmica}

O volume de 1,0 mol de metano, à pressão atmosférica, pode ser calculado pela Equação 7 .

$V_{C_{4}}=(22,4 \times T) / 273$

Equação 7
Na qual:

$V_{\mathrm{CH}_{4}}:$ volume equivalente a $1,0 \mathrm{~mol}$ de metano $(\mathrm{L})$;

$T$ : temperatura $\left({ }^{\circ} \mathrm{K}\right)$.

Adicionalmente, conforme Kuo (1996), a reação de combustão do metano é uma reação exotérmica, liberando 191,755 kcal/mol de energia, nas condições padrões de $25^{\circ} \mathrm{C}$ e 1,0 atmosfera. Visto isso, a energia térmica teoricamente produzida pode ser avaliada pela Equação 8.

$E_{p}=\left(\frac{Q_{C H_{4}}}{V_{C H_{4}}}\right) \times 191,755$

Equação 8

Na qual:

$E_{p}$ : Energia calorífica teórica produzida $(\mathrm{kcal} / \mathrm{d})$.

Considerando tal como Mendonça e Campos (2001) o calor específico do lodo igual ao da água $\left(\mathrm{c}=1 \mathrm{cal} / \mathrm{g} .{ }^{\circ} \mathrm{C}\right)$, tem-se a demanda de energia térmica a partir da Equação 9, que seria a energia efetivamente ganha pelo lodo.

$E_{g}=m \times c \times \Delta T$

Equação 9

Na qual:

$\mathrm{E}_{\mathrm{g}}$ : Energia térmica efetivamente ganha pelo lodo ( $\left.\mathrm{kcal} / \mathrm{d}\right)$;

m: massa de lodo (g);

c: calor específico do lodo (cal/g. $\left.{ }^{\circ} \mathrm{C}\right)$;

$\Delta T$ : gradiente de temperatura $\left({ }^{\circ} \mathrm{C}\right)$.

\section{Protocolo dos testes de secagem do lodo}

Para os testes de secagem do lodo, promoveu-se a sedimentação do lodo previamente ao tratamento térmico, uma vez que o lodo in natura apresenta maior capacidade de sedimentabilidade do que o lodo tratado termicamente. Dessa forma, alimentava-se o reator térmico e deixava-se o lodo repousar por um período mínimo de quatro horas, antes de se iniciar o tratamento térmico. Após esse período de sedimentação, efetuava-se o descarte do sobrenadante, reduzindo aproximadamente $35 \%$ do volume de lodo a ser higienizado. Durante os ensaios, o lodo foi mantido em constante agitação. A temperatura do lodo era monitorada de forma a atingir temperaturas próximas às encontradas nos testes de higienização descritos anteriormente.

Depois de higienizado, o lodo era aplicado a leitos de secagem, com diferentes cargas ( 5 e $10 \mathrm{kgST} / \mathrm{m}^{2}$ ), e seu desaguamento era monitorado. O programa de monitoramento consistiu em acompanhamento da concentração de sólidos totais (ST) nos leitos, como também da quantidade de volume drenado e evaporado.

Visando a comparar a secagem do lodo higienizado e do lodo in natura, este último foi descartado diretamente do reator UASB em leitos de secagem, com as mesmas cargas de sólidos aplicadas aos leitos que receberam lodos tratados termicamente. 
Tabela 2 - Cargas aplicadas aos leitos de secagem

\begin{tabular}{|c|c|c|c|c|}
\hline \multirow[b]{2}{*}{ Cargas de referência $\left(\mathrm{kgST} / \mathrm{m}^{2}\right)$} & \multicolumn{2}{|c|}{ Lodo in natura } & \multicolumn{2}{|c|}{ Lodo tratado termicamente } \\
\hline & Cargas reais $\left(\mathrm{kgST} / \mathrm{m}^{2}\right)$ & $\begin{array}{l}\text { Desvio da carga de } \\
\text { referência (\%) }\end{array}$ & Cargas reais $\left(\mathrm{kgST} / \mathrm{m}^{2}\right)$ & $\begin{array}{l}\text { Desvio da carga de } \\
\text { referência (\%) }\end{array}$ \\
\hline 5,0 & 5,4 & 8,0 & 5,6 & 12,0 \\
\hline 10,0 & 10,4 & 4,0 & 11,8 & 18,0 \\
\hline
\end{tabular}

O descarte do lodo excedente, em leitos de secagem, foi baseado em cargas de referência. Todavia, no cálculo das cargas reais, observou-se uma variação em torno do valor de referência. A Tabela 2 mostra as cargas de referência, as cargas reais aplicadas aos leitos e o desvio da carga real em relação à carga de referência tanto para o lodo in natura quanto para lodo tratado termicamente.

\section{Resultados e discussão}

\section{Avaliação da autossustentabilidade do sistema Produção teórica diária de metano}

Para a estimativa da produção teórica de metano, foram utilizados os resultados obtidos por Pontes (2003), que trabalhou no mesmo aparato experimental: vazão média afluente ao sistema $\left(\mathrm{Q}_{\text {méd }}\right)=$ $69 \mathrm{~m}^{3} / \mathrm{d}$; DQO média afluente $\left(\mathrm{S}_{\mathrm{o}}\right)=400 \mathrm{mg} / \mathrm{L}\left(0,40 \mathrm{kgDQO} / \mathrm{m}^{3}\right)$; DQO filtrada média efluente $(\mathrm{S})=80 \mathrm{mg} / \mathrm{L}\left(0,08 \mathrm{kgDQO} / \mathrm{m}^{3}\right)$; coeficiente de produção de sólidos do sistema $\left(\mathrm{Y}_{\mathrm{obs}}\right)=0,18 \mathrm{kgSVT} / \mathrm{kgD}$ $\mathrm{QO}_{\text {removida }}$. Com base nesses resultados experimentais e utilizando-se as Equações 1, 2 e 3, temos a Equação 10.

$$
\begin{array}{r}
D Q O_{C H_{4}}=69 \times[(0,40-0,08)-((0,18 \times 1,42) \times(0,40-0,08))]= \\
\text { Equação } 10
\end{array}
$$

Tendo sido a temperatura média ambiente do lodo no decorrer desta etapa de $24^{\circ} \mathrm{C}$, temos as Equações 11 e 12 .

$$
\begin{aligned}
& K(t)=\frac{(1 \times 64)}{[0,08206 \times(273+24)]}=2,626 \frac{\mathrm{kgDQO}}{\mathrm{m}^{3}} \\
& Q_{\mathrm{CH}_{4}}=\frac{16,44}{2,626}=6,26 \frac{\mathrm{m}^{3}}{\mathrm{~d}}
\end{aligned}
$$

\section{Produção real diária de metano}

Visto que a produção média de biogás no decorrer desta etapa foi de cerca de $6.350 \mathrm{~L} / \mathrm{d}$, e que o percentual de metano no biogás, segundo Pontes (2003), a partir de trabalho experimental realizado no mesmo aparato, foi de 76\%, forma-se a Equação 13.

$Q_{C H_{4}}=6350 \times 0,76=4826 \frac{L}{d}=4,83 \frac{m^{3}}{d}$

Equação 13

Comparando-se, portanto, a produção teórica à produção real de metano, percebe-se que a produção real foi menor do que a produção teórica, com produção real em torno de 75\% da produção teórica. Tal fato, segundo a bibliografia específica, pode se dever, dentre outros fatores, a perdas do metano com o efluente tratado, bem como para a atmosfera. No entanto, segundo Van Haandel e Lettinga (1994), na prática, as perdas estarão entre 20 e 50\% da produção teórica, estando os valores encontrados próximos desta margem de variação.

\section{Produção diária de lodo}

Segundo Pontes (2003), a vazão média afluente ao sistema foi de cerca de $69 \mathrm{~m}^{3} / \mathrm{d}$, com uma DQO média afluente em torno de 400 mg/L, e uma DQO filtrada média efluente em torno de 80 mg/L. Sendo assim, a fim de se determinar a produção diária de lodo no sistema e com base nas Equações 4, 5 e 6, temos as Equações 14 e 15.

$L_{\text {removida }}=(0,40-0,08) \times 69=22,1 \frac{\mathrm{kgDQO} O_{\text {removida }}}{d}$

Equação 14

$P_{\text {lodo }}=0,18 \times 22,1=3,98 \frac{\mathrm{kg}_{S V T}}{\mathrm{~d}}$

Equação 15

Tendo sido o percentual médio de SVT em torno de 60\%, teríamos a produção de lodo, em termos de ST, representada pela Equação 16.

$P_{\text {lodo }}=1,60 \times 3,98=6,36 \frac{\mathrm{kgST}}{\mathrm{d}}$

Equação 16

Uma vez verificado que a concentração média do lodo excedente no ponto de descarte foi de cerca 2,3\%, o volume teórico de lodo gerado diariamente pode ser calculado pela Equação 17.

$V_{\text {lodo }}=\frac{6,36}{(1020 \times 0,023)}=270 \frac{L}{d}$

Equação 17

Analisando-se os valores obtidos e com base nas considerações feitas por Von Sperling (1996), tem-se no sistema em estudo uma produção de lodos de cerca de 0,7 L/hab.dia, valor acima dos valores esperados para sistemas anaeróbios, segundo Andreoli, Von Sperling e Fernandes (2001), que seriam de 0,2 a 0,6 L/hab.dia.

\section{Produção e demanda teóricas de energia térmica}

Tendo sido a temperatura média ambiente do lodo de $24^{\circ} \mathrm{C}$, tem-se, com base nas Equações 7 e 8, a seguinte produção de energia térmica representada pelas Equações 18 e 19, resultante do processo de queima do biogás, a partir da produção diária real de biogás do sistema. 
$V_{\mathrm{CH}_{4}}=\left(\frac{22,4 \times(273+24,0)}{273}\right)=24,36 \frac{\mathrm{L}}{d}$

Equação 18

$E_{p}=\left(\frac{4826}{24,36}\right) \times 191,755=37989 \frac{\mathrm{kcal}}{\mathrm{d}}$

Equação 19

Sendo o volume teórico de lodo a ser tratado termicamente de $270 \mathrm{~L} / \mathrm{d}$, e tendo sido verificadas nos ensaios as temperaturas médias, ambiente e máxima, de 24 e $75^{\circ} \mathrm{C}$ (esta última após sete horas de ensaio), respectivamente, a energia efetivamente ganha pelo lodo foi alcançada por meio da Equação 20.

$E_{g}=m \times c \times \Delta T=(270 \times 1020) \times 1 \times(75-24)=14045 \frac{\mathrm{kcal}}{d} \quad$ Equação 20

Assim, comparando-se a energia térmica produzida $\left(E_{p}\right)$ e a energia efetivamente ganha pelo lodo $\left(\mathrm{E}_{\mathrm{g}}\right)$, verifica-se, conforme apresentado na Equação 21, um aproveitamento de 37\% entre o processo de queima do biogás e o de aquecimento do lodo, tendo resultado, portanto, em uma perda de $63 \%$ da energia térmica teoricamente produzida.

$\frac{E_{g}}{E_{P}}=\frac{14045}{37989}=0,37$

Equação 21

Mesmo tendo sido verificada uma baixa eficiência do sistema de aquecimento (37\%), percebe-se que, teoricamente, a energia térmica do biogás produzido em 24 horas seria suficiente para aquecer o volume teórico de lodo produzido neste mesmo período, frente ao aumento de temperatura verificado nos ensaios. Na prática, no entanto, a baixa concentração do lodo excedente (atípica para reatores UASB), verificada no decorrer dos ensaios, aponta como consequência no decorrer dos cálculos a necessidade de descarte de um volume elevado de lodo, caso se deseje atender ao procedimento de descarregar a massa de sólidos produzida em um dia, maior que a capacidade do reator térmico. Mais especificamente, o reator térmico tinha capacidade de receber um volume máximo em torno de 210 a 220 L, enquanto os cálculos resultaram em um volume de lodo a ser descartado diariamente em torno de $270 \mathrm{~L}$. Assim, embora os resultados constantes no item seguinte, referente à higienização, possam apresentar bons indícios da eficiência do processo de tratamento térmico do lodo, a avaliação quanto à autossustentabilidade frente à higienização fica parcialmente comprometida.
No entanto, sabe-se que lodos excedentes de reatores UASB apresentam concentrações típicas variando entre 3 e 4\%, as quais, se verificadas no presente aparato, viabilizariam o tratamento térmico de todo o lodo excedente produzido em um dia, permitindo assim o estudo da autossustentabilidade. Finalmente, embora tal avaliação não tenha sido possível, o volume de lodo ensaiado equivale a cerca de $80 \%$ da produção volumétrica teórica diária, dando fortes indícios de que a análise dos resultados encontrados talvez possa ser extrapolada para o volume 20\% maior. Destaca-se, ainda, que o tratamento térmico objetivando a higienização, no qual se empregou somente o biogás como fonte de energia térmica, foi desenvolvido no decorrer de cinco horas, tendo sido atingida a temperatura média máxima de $67^{\circ} \mathrm{C}$, embora a produção diária fosse suficiente para manter o lodo sob tratamento térmico por cerca de sete horas. Esse fato também contribui para uma avaliação positiva quanto à autossustentabilidade do sistema.

\section{Avaliação da higienização do lodo submetido ao tratamento térmico}

Em uma primeira etapa, tal como apresentado por Borges (2004), a metodologia de trabalho apresentada foi desenvolvida em um aparato experimental em escala piloto, com a mesma configuração do trabalho em análise (reator UASB + reservatório de biogás + reator térmico). Nesta primeira etapa, na qual 16 testes foram realizados em quatro situações distintas de ensaio, identificou-se, em todas as situações, a total higienização do lodo submetido ao tratamento térmico a partir de diferentes relações entre os parâmetros temperatura e tempo de aquecimento, conforme já relatado na literatura específica. Neste aparato em escala piloto, empregando-se somente o biogás produzido em um dia, para tratar termicamente o lodo produzido em um dia, a total higienização foi verificada em amostras coletadas após duas horas do início do tratamento, quando a temperatura verificada encontrava-se em torno de $54^{\circ} \mathrm{C}$.

Sendo assim, interpretando-se, a partir dos resultados do trabalho em escala piloto, que a total higienização do lodo produzido em um dia empregando-se o biogás produzido em um dia seria certamente alcançada no aparato em escala de demonstração, somente três ensaios referentes a esta análise foram realizados, conforme resultados apresentados na Tabela 3 e na Figura 2.

Tabela 3 - Estatística descritiva referente às análises de ovos de ascaris lumbricoides

\begin{tabular}{|c|c|c|c|c|c|c|}
\hline \multirow[b]{2}{*}{ Tempo de exposição (horas) } & \multicolumn{3}{|c|}{ Ovos viáveis (Número de ovos/gMS) } & \multicolumn{3}{|c|}{ Ovos totais (Número de ovos/gMS) } \\
\hline & 0 & 3 & 5 & 0 & 3 & 5 \\
\hline Temperatura $\left({ }^{\circ} \mathrm{C}\right)$ & 25 & 55 & 67 & 25 & 55 & 67 \\
\hline Número de amostras & 3 & 2 & 3 & 3 & 2 & 3 \\
\hline Média & 107 & 35 & 0 & 160 & 193 & 222 \\
\hline Máximo & 139 & 69 & 0 & 204 & 245 & 314 \\
\hline Mínimo & 46 & 0 & 0 & 112 & 142 & 149 \\
\hline Eficiência de inativação (\%) & 0 & 68 & 100 & 0 & -21 & -38 \\
\hline
\end{tabular}


Embora o biogás armazenado fosse suficiente para tratar termicamente o lodo por um período de cerca de sete horas, optouse, com base em testes realizados referentes ao desenvolvimento da curva de temperatura/tempo de aquecimento, no trabalho desenvolvido no aparato em escala piloto (BORGES, 2004) e na literatura específica, por se coletarem as amostras em um intervalo de tempo máximo de cinco horas. Analisando-se os resultados apresentados na Tabela 3 e na Figura 2, verifica-se a total higienização do lodo após cinco horas de tratamento térmico, quando a temperatura encontrava-se a $67{ }^{\circ} \mathrm{C}$. Tais resultados confirmam ainda a auto-sustentabilidade do sistema, com relação à possibilidade de higienização térmica do lodo excedente, empregando-se como fonte de energia térmica somente o biogás produzido pelo reator UASB, reafirmando assim os resultados teóricos encontrados no balanço térmico.

Com relação ao número total de ovos, observa-se um aumento, ao invés de diminuição, com o decorrer do tempo de aquecimento do lodo. Tais resultados, no entanto, não representam, de modo algum, um aumento do número de ovos. Uma possível explicação para tais números pode ser uma maior eficiência do método de recuperação empregado, à medida que as amostras eram coletadas, visto que nenhum método é $100 \%$ eficiente. Com o passar do tempo de tratamento térmico e com o aquecimento crescente do lodo, pode ter ocorrido a desintegração física de sólidos e grânulos presentes no lodo, facilitando assim uma melhor recuperação e, portanto, uma maior eficiência na contagem dos ovos de Ascaris lumbricoides presentes nas amostras.

\section{Avaliação da desidratação do lodo}

As cargas de lodo aplicadas nos leitos de secagem ( 5 e $10 \mathrm{kgST} / \mathrm{m}^{2}$ ) estiveram abaixo dos valores recomendados pela norma NBR 12209/92 da ABNT, uma vez que, em testes preliminares, foi observado que os lodos tratados termicamente apresentavam maior dificuldade de secagem. Em todos os testes, a concentração inicial do lodo in natura foi inferior à do lodo tratado termicamente, que passou pela etapa de sedimentação antes de se iniciar a higienização, reduzindo-se a quantidade de água no lodo.

A capacidade de desaguamento do lodo está diretamente relacionada ao tipo de sólido e à forma como a água está ligada às partículas sólidas (SMOLLEN, 1988; GONÇALVES; LUDUVICE; VON SPERLING, 2001). Dessa forma, o período de secagem e o aumento do teor de sólidos do lodo estão relacionados às quatro categorias de água que podem estar presentes no lodo (VESILIND, 1994; SMOLLEN, 1988): i) água livre; ii) água intersticial; iii) água vicinal (ou superficial); e iv) água intracelular (ou de hidratação). A evolução da concentração de sólidos totais no lodo in natura e no lodo tratado termicamente, para as cargas de 5 e $10 \mathrm{~kg} \mathrm{ST} / \mathrm{m}^{2}$, é apresentada nas Figuras 3 e 4 , respectivamente.

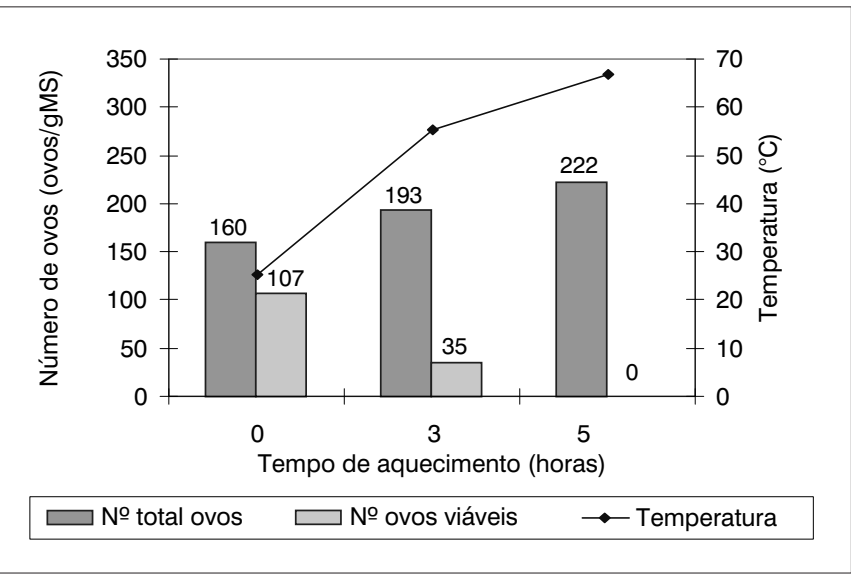

Figura 2 - Variação do número de ovos de helmintos (Ascaris lumbricoides)

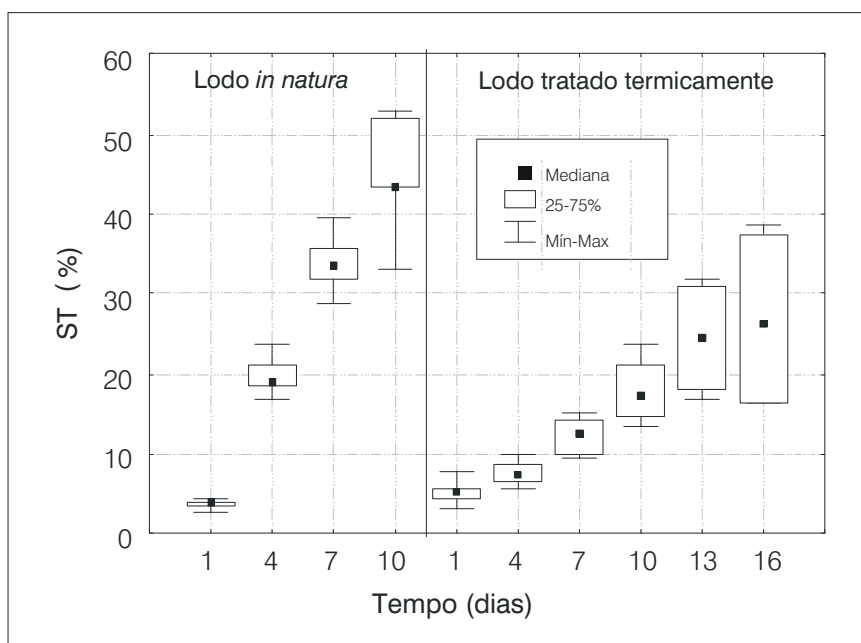

Figura 3 - Evolução da concentração de sólidos totais no lodo tratado termicamente, com sedimentação prévia, e no lodo in natura: carga de $5 \mathrm{kgST} / \mathrm{m}^{2}$

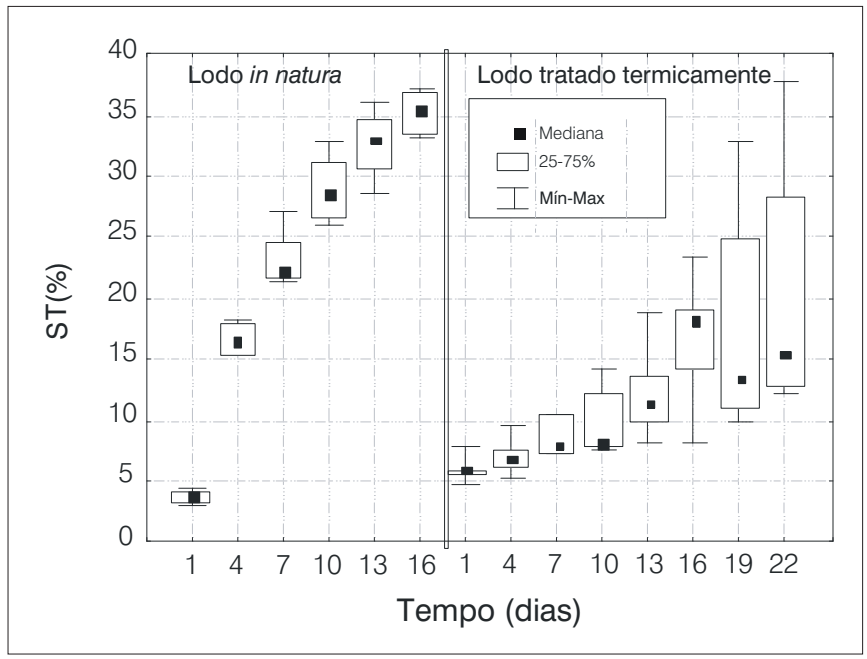

Figura 4 - Evolução da concentração de sólidos totais no lodo tratado termicamente, com sedimentação prévia, e no lodo in natura: carga de $10 \mathrm{kgST} / \mathrm{m}^{2}$ 


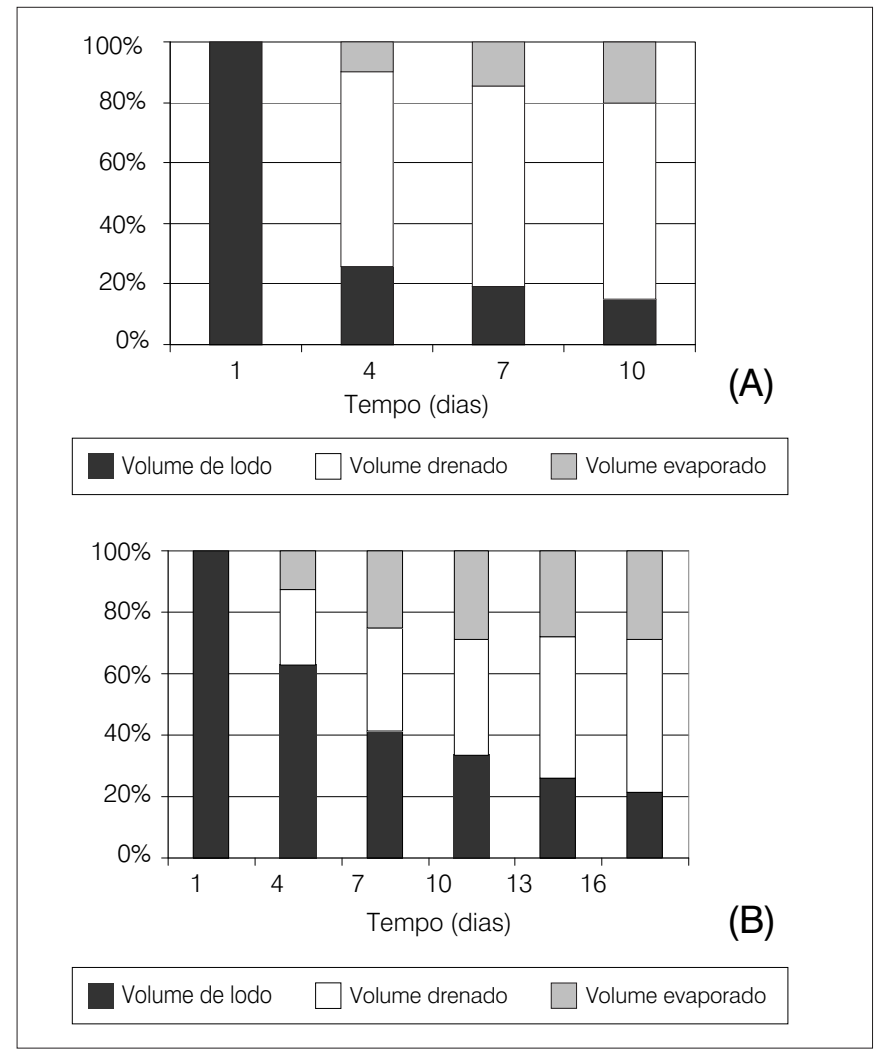

Figura 5 - Distribuição do volume para lodo in natura (A) e lodo tratado termicamente (B): carga de $5 \mathrm{kgST} / \mathrm{m}^{2}$

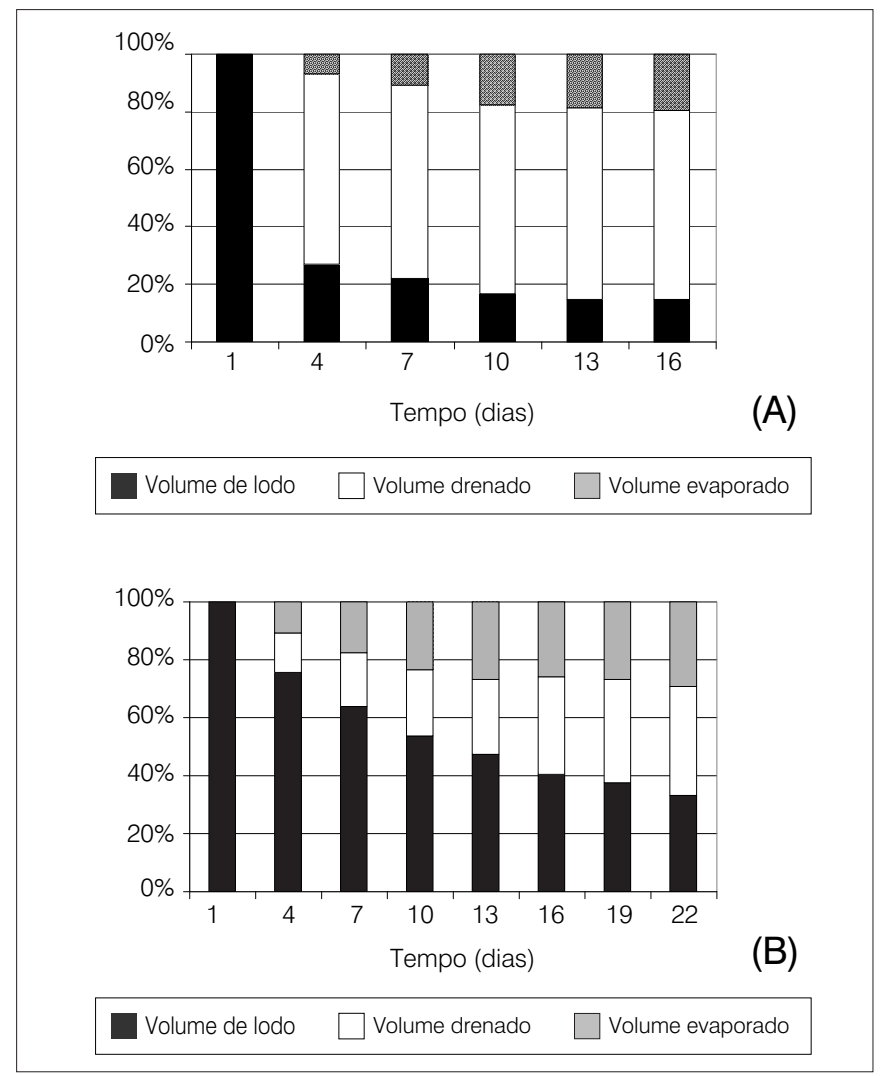

Figura 6 - Distribuição do volume para lodo in natura $(\mathrm{A})$ e lodo tratado termicamente (B): carga $10 \mathrm{kgST} / \mathrm{m}^{2}$
Para as duas cargas testadas, o lodo in natura atingiu concentração superior a 35\% de sólidos totais em um período menor ou igual a 16 dias. No entanto, para a carga de $10 \mathrm{kgST} / \mathrm{m}^{2}$, observa-se uma menor taxa de secagem do lodo e, consequentemente, um aumento no tempo de secagem. O teor de sólidos do lodo in natura atingiu, em sete dias, 33,7 e 22,2\% para as cargas de 5 e $10 \mathrm{kgST} / \mathrm{m}^{2}$, respectivamente. O mesmo comportamento foi observado para o lodo tratado termicamente, que quando aplicado em leitos, com as mesmas cargas (5 e $10 \mathrm{kgST} / \mathrm{m}^{2}$ ), atingiram, respectivamente, 12,4 e 7,9\% de sólidos totais em sete dias (Figuras 3 e 4 ).

A dificuldade de secagem do lodo tratado termicamente pode ser causada pelo rompimento dos flocos quando passam por aquecimento. A água livre passa a ser intersticial, pois o material intracelular é solubilizado nesta água. Outro fator que pode dificultar a secagem do lodo tratado termicamente é a retirada de parte da água livre drenável na etapa prévia de sedimentação do lodo, conforme discutido adiante.

Para se avaliarem as parcelas de água perdidas por drenagem e por evaporação para o lodo in natura e para o lodo tratado termicamente, foram construídos os gráficos das Figuras de 5 e 6, que apresentam a distribuição, no decorrer do tempo, das três parcelas de volume, para as duas cargas testadas.

Para todas as cargas testadas, observou-se que o lodo tratado termicamente perde mais água por evaporação do que o lodo in natura, sendo que este último, já nos primeiros dias de secagem, perde grande quantidade de água por drenagem. Esse comportamento pode ser explicado pela alteração dos tipos de água presentes no lodo. O lodo in natura apresenta grande quantidade de água livre, que é facilmente perdida por drenagem. Já o lodo tratado termicamente apresenta grande viscosidade e, quando disposto nos leitos de secagem, sedimenta, formando uma camada pouco permeável no fundo do leito, o que dificulta a passagem da água por seus interstícios. Essa grande viscosidade do lodo tratado termicamente pode ser explicada pela quebra dos flocos maiores do lodo, fazendo com que parte da água livre se transforme em água intersticial, através da solubilização do conteúdo celular dos flocos.

Uma vez que o lodo tratado termicamente apresenta maior dificuldade de secagem que o lodo in natura, verifica-se que o tempo de secagem necessário para o lodo atingir uma mesma concentração de sólidos é consideravelmente maior para o lodo tratado termicamente (Figura 7). Nota-se, também, que quanto maior a carga aplicada maior o tempo de secagem e, consequentemente, maior requisito de área.

\section{Conclusões}

Com relação ao aparato experimental, conclui-se que o sistema simplificado empregado, composto por reator UASB + reservatório de biogás + reator térmico, apresenta-se como uma promissora alternativa para o emprego do biogás gerado em sistemas anaeróbios 
de tratamento de esgotos e para o tratamento de lodos excedentes, mostrando-se de potencial relevância para o Brasil e para países em desenvolvimento.

A partir do balanço térmico desenvolvido (demanda teórica de energia térmica $=14.045 \mathrm{kcal}$; energia térmica teoricamente produzida $=15.195 \mathrm{kcal}$, já tendo sido considerada uma perda de $60 \%$ no processo de aquecimento), e também conforme verificado nos ensaios realizados, conclui-se que o biogás gerado em sistemas anaeróbios de tratamento de esgotos, particularmente reatores UASB, é suficiente para se alcançar a higienização térmica de todo o lodo excedente produzido neste sistema de tratamento de esgotos, sendo esta uma solução totalmente autossustentável em relação à higienização de lodos. Pode haver, ainda, um excedente de biogás e, portanto, de energia que pode ser empregado em outra finalidade.

A relação temperatura/tempo de exposição, com base nos resultados apresentados e na literatura específica, permite combinações variadas para a eliminação/inativação de micro-organismos patogênicos, em especial ovos de Ascaris lumbricoides. No presente estudo, a total higienização foi verificada em amostras coletadas após cinco horas de tratamento térmico, quando a temperatura encontrava-se a $67^{\circ} \mathrm{C}$, tendo sido iniciado o tratamento em temperatura ambiente.

O lodo tratado termicamente apresentou rendimento de desaguamento bem inferior ao do lodo in natura. À medida que se aumenta a carga aplicada, ocorre uma diminuição da taxa de secagem do lodo e, consequentemente, um aumento no tempo de secagem do lodo. Para um período de secagem de sete dias, o teor de sólidos do lodo in natura atingiu 33,7 e $22,2 \%$, para as cargas de 5 e $10 \mathrm{kgST} / \mathrm{m}^{2}$, respectivamente. Para o mesmo período e mesmas cargas, os teores de sólidos verificados no lodo tratado termicamente foram de 12,4 e 7,9\%, respectivamente, concentrações cerca de três vezes menores.

O lodo tratado termicamente perde menos água por drenagem do que o lodo in natura, sendo que este último, já nos primeiros três a quatro dias, perde grande volume de água (mais de 60\% do volume total) por meio da drenagem da água livre, enquanto no lodo submetido ao tratamento térmico, a água drena em menor quantidade e mais lentamente devido à formação de uma camada pouco permeável de lodo no fundo dos leitos.

O lodo tratado termicamente perde mais água por evaporação do que por drenagem, sendo o processo de secagem fortemente influenciado pela temperatura ambiente e pela umidade relativa do ar.
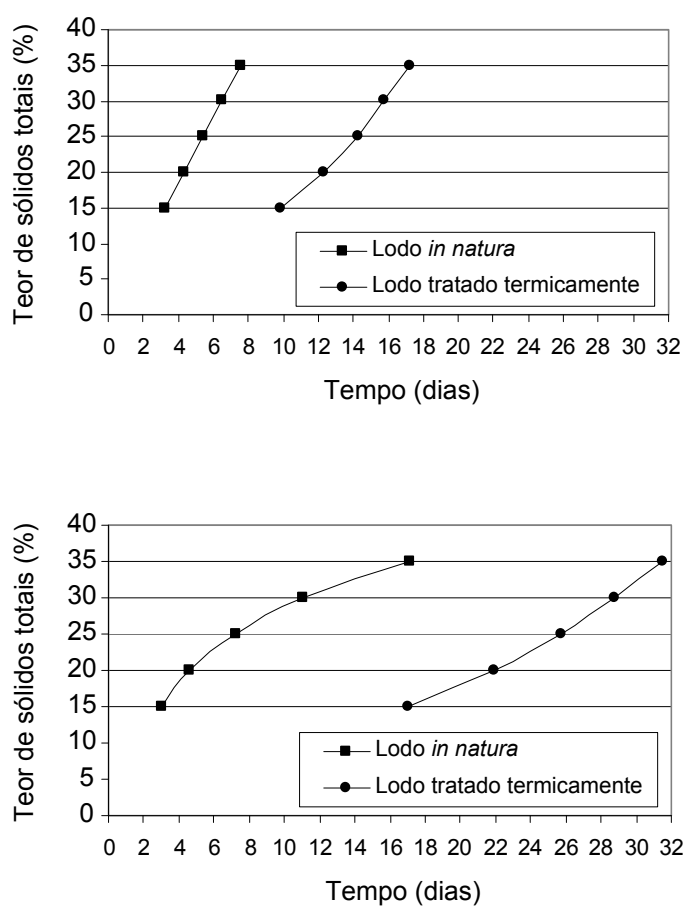

(B)

Figura 7 - Tempo de secagem do lodo para as cargas de $5(\mathrm{~A})$ e $10 \mathrm{kgST} / \mathrm{m}^{2}(\mathrm{~B})$

Considerando que os elevados tempos e áreas de secagem podem, de certa forma, inviabilizar a retirada de umidade do lodo tratado termicamente, a utilização agrícola do lodo higienizado deve ser feita preferencialmente nas imediações da própria ETE, de modo a reduzir os custos de transporte.

\section{Agradecimentos}

Os autores agradecem à Financiadora de Estudos e Projetos (Finep) e à Fundação de Amparo à Pesquisa do Estado de Minas Gerais (Fapemig) pelo apoio financeiro à pesquisa, à Coordenação de Aperfeiçoamento de Pessoal de Nível Superior (Capes) e ao Conselho Nacional de Desenvolvimento Científico e Tecnológico (CNPq) pelas bolsas de mestrado e doutorado dos autores Eduardo Borges, Valéria Godinho e Deneb Bejar, e à Companhia de Saneamento de Minas Gerais (Copasa) pela constante contribuição no decorrer do trabalho. 


\section{Referências}

ANDERSON, N.J. et al. Complete characterization of thermally treated sludges. Water Science and Technology, v. 46, n. 10, p. 51-54, 2002.

ANDREOLI, C.V.; Von SPERLING, M.; FERNANDES, F. Princípios do tratamento biológico de águas residuárias; Lodo de esgotos: tratamento e disposição final. 1. ed. Belo Horizonte/Paraná: Departamento de Engenharia Sanitária e Ambiental, UFMG/Companhia de Saneamento do Paraná, 2001.

BORGES, E.S.M. Tratamento térmico de lodo anaeróbio a partir da queima do biogás produzido em reator UASB objetivando a higienização e a melhoria da biodisponibilidade e biodegradabilidade da fração orgânica. 254 f. Tese (Doutorado em Saneamento, Meio Ambiente e Recursos hídricos) - Escola de Engenharia, Universidade Federal de Minas Gerais, Belo Horizonte, 2004.

CHERNICHARO, C.A.L. Princípios do tratamento biológico de águas residuárias; reatores anaeróbios. 1. ed. Belo Horizonte: Departamento de Engenharia Sanitária e Ambiental, UFMG, 1997. v. 5.

FITZPATRICK, J. Sludge processing by anaerobic digestion and superheated steam drying. Water Research, Great Britain, v. 32, n.10, p. 2897-2902, 1998.

FRANÇA, M. Avaliação da biodegradabilidade e da biodisponibilidade do lodo de esgoto anaeróbio termohidrolisado pelo uso do biogás. 154 f. (Mestrado em Engenharia Ambiental) - Setor de Engenharia Sanitária e Ambiental, Universidade Federal de Santa Catarina, Florianópolis, 2002.

GONÇALVES, R.F.; LUDUVICE, M.; Von SPERLING, M. Remoção de umidade de lodos de esgotos. In: ANDREOLI, C.V.; Von SPERLING, M.; FERNANDES, F. (Ed.). Princípios do tratamento biológico de águas residuárias, Vol. 6: lodo de esgoto: tratamento e disposição final. Belo Horizonte/Paraná: Departamento de Engenharia Sanitária e Ambiental da UFMG/Companhia de Saneamento do Paraná, 2001. p. 159-259.

KUO, K.K. Principles of combustion. Singapore: Wiley-Interscience Publication, 1996.
MENDONÇA, L.C.; CAMPOS, J.R. Exploitation of biogas on dehydration and disinfection of UASB reactors sludge. In: WORLD CONGRESS ANAEROBIC DIGESTION, 9, 2001, Antwerpen, Belgium. Anaerobic Conversion for Sustainability. Proceedings, Part 1, Antwerpen, p. 679-684 2001.

MEYER, K.B.; MILLER, K.D.; KANESHIRO, E.S. Recovery of ascaris eggs from sludge. The Journal of Parasitology, v. 64, n. 2, p. 380-383, Apr. 1978.

PANTER, K. Cambi thermal hydrolysis: getting the bugs out of digestion and dewatering. In: EUROPEAN BIOSOLIDS AND ORGANIC RESIDUALS CONFERENCE, 3, Wakefield, England, 1998.

PONTES, P.P. Reatores UASB aplicados ao tratamento combinado de esgotos sanitários e lodo excedente de filtro biológico percolador. 220 f. Tese (Doutorado em Saneamento, Meio Ambiente e Recursos Hídricos) - Escola de Engenharia, Universidade Federal de Minas Gerais, Belo Horizonte, 2003.

SMOLLEN, M. Moisture retention characteristics and volume reduction of municipal sludges. Water SA, v. 14, n. 1, p. 25-28, 1988.

VAN HAANDEL, A.C.; LETTINGA, G. Tratamento anaeróbio de esgotos: um manual para regiões de clima quente. Campina Grande: Fotolitos e Impressão Gráfica OFF-SET, 1994.

VESILIND, P.A. The role of water in sludge dewatering. Water Enviroment Research, v. 6, n. 1, p. 4-11, 1994

VON SPERLING, M. Princípios do tratamento biológico de águas residuárias. introdução à qualidade das águas e ao tratamento de esgotos. 2. ed. Belo Horizonte: Departamento de Engenharia Sanitária e Ambiental/UFMG, 1996. v. 1

WEISZ, N. et al. Sludge disintegration with thermal hydrolysis - Cases from Norway, Denmark, and United Kingdom. In: WORLD WATER CONGRESS OF THE INTERNATIONAL WATER ASSOCIATION (IWA), 1, Paris. Conference Preprint. Book 4. Paris: IWA, 2000, p. 288-295. 